\title{
MARKETWATCH
}

\section{Global Infectious Disease Surveillance And Health Intelligence}

\author{
The development of effective, interconnected systems of infectious \\ disease surveillance is essential to our survival.
}

\section{by Stephen S. Morse}

ABSTRACT: Current concerns about the spread of infectious diseases, especially unexpected ("emerging") infections such as pandemic influenza or severe acute respiratory syndrome (SARS), have renewed focus on the critical importance of global early warning and rapid response. Although considerable progress has been made, many gaps remain. $A$ number of the gaps can be addressed through increased political will, resources for reporting, improved coordination and sharing of information, raising clinicians' awareness, and additional research to develop more rigorous triggers for action. The increasing availability of communications and information technologies worldwide offers new opportunities for reporting even in low-capacity settings. [Health Affairs 26, no. 4 (2007): 1069-1077; 10.1377/hlthaff.26.4.1069]

$\mathrm{I}$ NFECTIOUS DISEASES REMAIN the ma jor causes of illness and death worldwide. ${ }^{1}$ Current concern includes $\mathrm{H} 5 \mathrm{Nl}$ influenza (avian flu), which has caused over 170 human deaths in twelve countries and is still ongoing. Could this avian virus become more transmissible person-to-person? With present knowledge, this cannot be determined unless it actually occurs. If $\mathrm{H} 5 \mathrm{Nl}$ evolved to become efficiently transmitted, it could cause the next influenza pandemic. ${ }^{2}$ Or, quite possibly, another as yet unnoticed flu virus could make the leap. Although the 1918 influenza pandemic might be unique, it caused an estimated fifty million deaths worldwide, making it one of the greatest natural disasters in history. $^{3}$

It is widely agreed that the key to control of any pandemic is early identification and rapid response. ${ }^{4}$ This must begin with effective early warning. However, given the current state of surveillance and the expected delays in reporting and lab confirmation, few are optimistic about this happening. ${ }^{5}$ A few years ago, the severe acute respiratory syndrome (SARS) virus infected more than 8,000 people, causing 774 recorded deaths. ${ }^{6}$ The worldwide SARS outbreak began with thirteen people infected in Hong Kong. If others had been warned in time, perhaps cases and deaths in Vietnam or Toronto could have been prevented.

SARS and human infections with $\mathrm{H} 5 \mathrm{Nl}$ influenza, as well as HIV/AIDS (which has exacted a terrible toll in much of the world, especially Africa), are examples of "emerging infections," which were unknown to medicine until recently. ${ }^{7}$ It is likely that the emergence of such diseases will continue and possibly even increase in the future, making early warning increasingly critical. ${ }^{8}$

StephenMorse(ssm20@columbiacedu) is an associate professor of clinical epidemiology in the Mailman School of Public Health, Columbia University, in New York City. 


\section{A Brief Surveillance Lexicon}

- "Health intelligence." This paper deals specifically with infectious disease surveillance (a term developed by the late Alexander Langmuir at the Centers for Disease Control and Prevention, or CDC) and response, but many of the issues discussed here apply to other types of health events such as noncommunicable diseases. ${ }^{9}$ Because there are potentially many different types of disease reporting and health information, I suggest the term "health intelligence" to refer broadly to usable information on events of public health significance. Analogously, the CDC and the Department of Homeland Security (DHS) have referred to "BioIntelligence," while Canada has a program, discussed later, called the Global Public Health Intelligence Network.

There are a variety of classical data sources for health intelligence, including clinical reports, notifiable disease reporting, lab reports, pathology results, registries, and death records. Traditionally, clinical reports have been most important. In general, all health intelligence originates at the local level, usually as clinical information. People are fond of referring to the "proverbial astute clinician" who notices the deviation from the norm. Usually, clinical cases are identified and samples from patients are tested in the laboratory to identify the pathogen. Epidemiologic investigation, to determine source of infection and additional exposures, is usually carried out in parallel and, together with laboratory identification, helps inform disease control measures. ${ }^{10}$

- "Syndromic surveillance." In recent years, "syndromic surveillance" has also been developed." This term once referred to the use of clinical syndromes as criteria for reporting. ${ }^{12}$ Now, it usually means data collected from automated nondiagnostic systems such as pharmacy records, ambulance call categories, personnel absences, or emergency department (ED) chief complaints. ${ }^{13}$ Although this approach is very promising, ways to optimize its use are still in development. ${ }^{14}$

- Local knowledge. In most areas of the world, there is still no substitute for local knowledge. Wilbur Downs, at Yale, referred to the "umbrella of malaria" in tropical regions, and it requires local medical knowledge to differentiate a case of, say, yellow fever from the many cases of malaria found in the same areas..$^{15}$ After Western medicine "discovered" AIDS, researchers found African accounts of people getting "slims" disease: AIDS by another name. The 1995 Ebola virus outbreak in Kikwit, Congo, was first identified in May and immediately galvanized a rapid world response. However, the outbreak might have started several months before, with recognition delayed by an outbreak of bloody diarrhea caused by Shigella (leading James Hughes, then director of the CDC National Center for Infectious Diseases, to remark that although it would have been useful to have the reagents to diagnose Ebola locally, it would have been equally useful just to be able to diagnose shigellosis routinely). ${ }^{16}$

\section{Surveillance Systems Around The World}

Most surveillance systems are passive and disease-specific. This means that there are numerous individual systems, which often lack information-sharing mechanisms, and "new" or currently unknown diseases might be picked up only haphazardly. Once a newly recognized disease is sufficiently important to warrant notice, it, too, may eventually get its own dedicated surveillance system (HIV/ AIDS, for example). With such fragmentation, the system can only be reactive at best. Furthermore, each country has its own arrangement, reflecting the organization of its public health system.

U.S. surveillance systems. In the United States, each state is responsible for surveillance and reporting, using a consensus list of reportable diseases by the Council of State and Territorial Epidemiologists (CSTE). These diseases are reported locally to the state and then by the state to the CDC. States may also add other diseases that they wish local physicians to report. Outbreak assistance from the CDC must be requested by the state (or, in some cases, a large city). Although the CDC can provide aid only when requested, in prac- 
tice, it has liaison officers in many state and large city health departments and may be involved at least informally.

Other countries' systems. Other countries with federal systems generally have similar arrangements, while many countries have more centralized surveillance and control functions to provide assistance to localities. Some regional capabilities exist. In addition to national surveillance programs, western $\mathrm{Eu}$ rope has "Eurosurveillance" (a weekly epidemiological bulletin consolidating national surveillance results) and the recent beginnings of a "European CDC," with headquarters in Stockholm.

Central control and effectiveness. It is widely assumed that countries with highly centralized political control have more-effective

\begin{tabular}{|} 
"The state of global \\
infectious disease \\
surveillance and \\
response in most of \\
the world varies from \\
weak to virtually \\
nonexistent."
\end{tabular}

tives intended to provide liaison and communication with national governments.

One recent development at the WHO seems especially promising. The WHO International Health Regulations (IHR) provide the instructions for nations to report diseases found in incoming travelers. The IHR formerly required international reporting of only cholera, plague, yellow fever, and (until it was eradicated) smallpox, but the regulations have recently been revised to encompass a broader syndrome-oriented approach that would accommodate warnings of unknown infectious diseases. According to the WHO, "The broadened purpose and scope of the new IHR (2005) are to 'prevent, protect against, control and provide a public health response to the international spread of disease and...avoid surveillance systems. This assumption is mistaken; there is no simple relationship between central control and effective surveillance. In China, it was often remarked in the world press during the SARS outbreak that reporting relations between localities and the capital were very weak. ${ }^{17}$ In some countries there may also be a fear of political repercussions.

- Local agricultural and animal diseases. Many countries also have reportable agricultural diseases and veterinary diagnostic laboratories. As many diseases of concern are zoonotic (from other animal species), it is necessary for the veterinary and human disease systems to share information and diagnostic resources. The U.S. Department of Agriculture maintains a reference diagnostic laboratory, as well as agricultural extension stations and field agents to help farmers; therefore, unlike the human health community, case identification does not rely exclusively on local clinicians to notice disease problems.

Work of the WHO. At the international level, the World Health Organization (WHO) is the coordinating body but is dependent on its member states for reporting. The WHO has a number of country and regional representa- unnecessary interference with international traffic and trade'."18 Although developing and gaining acceptance for the new IHR approach has taken time and patience, it seems well along now. Implementing the new IHR (2005) will require each nation to have a real-time event-monitoring system and strengthened surveillance capabilities. However, each nation must fund the program from its own resources, and many will require financial help and other incentives.

\section{Outlook For Global Surveillance Capabilities}

Despite the gaps noted, with all of these capabilities, one might expect the outlook to be rosy. Unfortunately, as the spread of SARS attests, this is not the case. It is widely recognized that the state of global infectious disease surveillance and response is variable and, in most of the world, varies from weak to virtually nonexistent. This is true despite the fact that infectious diseases of possible significance can originate anywhere in the world, and many have originated in places with limited surveillance capacity. Several factors combine to limit global capabilities. 
Health's low priority on government agendas. First, despite its life-and-death nature, health does not generally have a high priority in most governments, compared with other ministries. Other than educating policymakers, I see little that can be done to change this situation. In many cases, ministerial interests may be divergent. Agriculture ministries might wish to increase density of farmed animals to reduce production costs, while public health experts might warn of the potential risks to human health of doing so.

Delayed reporting of disease information. Second, governments are often reluctant to report disease information for fear of political embarrassment, economic or trade repercussions, or concern that it may make the government look ineffectual. China began to experience an outbreak of SARS in November 2002 (if not earlier) but did not begin reporting it until February 2003, by which time the government listed 305 cases. $^{19}$

Thus, there are many perceived disincentives for reporting disease. Are there any incentives? I think that the answer is: too few. After the SARS outbreak, it was hoped that the tremendous impact on Asian travel, and the corresponding loss of revenue largely attributable to delayed reporting, would encourage governments to be more proactive in reporting diseases. ${ }^{20}$ Anecdotal reports from Toronto suggest that Canadians felt punished, not rewarded, for promptly reporting SARS cases, although it is likely that Canada will continue to be as forthcoming as in the past. ${ }^{21}$ Despite its earlier experiences with SARS, China did not report a November 2003 human H5Nl influenza case until 2006.22 This is not to single out China, which has been doing a great deal to strengthen its disease surveillance capacity. ${ }^{23}$ Delays in reporting are simply all too frequent worldwide.

Competition for public health resources. Although infectious disease activities may be among those most evident to the public, they represent only a portion of the many essential functions of public health and may fall victim to perceptions of competing priorities for limited resources. In the 1960s, the WHO's governing body, the World Health Assembly, held technical discussions on global surveillance of infectious diseases, but these were never followed up on, reportedly because of concerns that surveillance might compete with primary health care resources for developing countries. ${ }^{24}$ In my view, this is a false dichotomy, as both are needed, and (as we will later see) surveillance activities both benefit from the presence of a health infrastructure and can usefully add to its effectiveness.

It is essential to provide additional incentives. Different incentives will likely apply at different levels. At the local or district level, training, feedback, and epidemiological or clinical assistance to the reporting clinicians and local public health are possible incentives. At the country level, financial incentives and resources are needed to encourage reporting as well as to expand the reach of the primary health care and communications infrastructures. Other psychological incentives, such as increased national prestige for recognizing an unusual disease, should also be considered. Encouragement from the international community, to overcome a country's fear of adverse consequences and help leverage resources, is also necessary.

\section{An Attempt To Reduce The Fragmentation Of Surveillance Systems}

The plan. In an attempt to reduce what many (including myself) saw as the fragmentation of disease surveillance systems and the lack of global capacity, the Program for Monitoring Emerging Diseases (ProMED) was begun in 1993 by a group of concerned scientists, under the auspices of the Federation of American Scientists. At meetings in Geneva and elsewhere, a steering committee recommended developing a system of regional centers to identify and respond to unusual disease outbreaks. ${ }^{25}$ This elaborated on the system D.A. Henderson proposed at a 1989 National Institutes of Health (NIH) meeting. ${ }^{26}$

One would think that it should be fairly simple to network regional centers of excellence to augment official systems and allow 
mutual cooperation, whether through the WHO or through regional intergovernmental organizations. On the other hand, if diseases can emerge anywhere, how can one get reports from literally everywhere? The latter seemed the harder task, so we decided to try tackling the easier one first.

The original ProMED concept, from the mid-1990s, was to plan a system that could provide early warning for both emerging (currently unknown or unanticipated) infections as well as familiar ones. The strategy developed was vigilance for unusual clinical presentations of special concern (such as encephalitis or acute respiratory distress with fever in adults); a set of minimum microbiology capabilities at each site, to identify common diseases; and a system to refer unidentifiable samples to successively larger reference labs, through the network, for possible identification. The plan also included epidemiologic capacity, which could be provided rapidly through the network if needed. ${ }^{27}$

- Connectivity but no global network. It soon became apparent that the sixty or so steering committee members from around the globe had no consistent means of communication with the chair (myself) or others in the network. As a result, in 1994 ProMED connected all of its steering committee members by e-mail—at that time still novel. Some of the members were in such underserved places that satellite uplinks were required (provided through another nonprofit, SatelLife, in Boston). The system, originally envisioned as a direct scientist-to-scientist network, rapidly grew into a prototype outbreak reporting and discussion list, especially after the 1995 Ebola outbreak. Open to all, and edited (moderated) by a group of scientists, public health, and infectious disease experts, ProMED-mail (now a program of the International Society for Infectious Diseases) has grown along with the Internet and now has more than 30,000 subscribers in some 155 countries. Among the notable outbreaks first reported on ProMEDmail were the early reports of SARS in China (10 February 2003) and Toronto; a multistate outbreak of meningococcal meningitis, in both the United Kingdom and the United States, in 1995; H5Nl influenza in Indonesia, November 2003; and fatalities in China in 2005 attributed to Streptococcus suis. ${ }^{28}$ In fact, with the rapid growth of the Internet over the past decade, it is now possible to have reports from much of the world. At the same time, although steps have been made toward the original goal of a network of periurban centers, there is still no fully functional global network of the sort envisioned by Henderson or in the original 1996 ProMED proposal. ${ }^{29}$ Political will at the leadership level and resource constraints remain the missing elements. So much for achieving the simpler goals first.

\section{Impact Of The Communications Revolution}

Examples of electronic systems. The information and communications "revolutions" of our time are having major impacts. During the SARS outbreak, the WHO and collaborating scientists made very effective use of modern communications, such as e-mail and video teleconferences. The establishment of ProMED-mail in 1994 inspired the development of several other systems, including the CDC's Epi-X and an e-mail discussion list of the Infectious Diseases Society of America. When ProMED-mail started, virtually no press content was available electronically. Later in the 1990s, news reports from around the world first became available on the Web, and the Canadian government started an innovative limited-access system, the Global Public Health Intelligence Network (GPHIN), which electronically searches the World Wide Web to identify possible news reports of disease outbreaks. In the past, most of the content on ProMED-mail had come as postings from subscribers, many of whom are scientists, physicians, or public health officials. In recent years, an increasing amount of the content on ProMED-mail, GPHIN, and other electronic sources is gleaned from press reports and other open sources.

- Press reports. Although press reports have the advantage of some immediacy, they often lack the specificity of reports by knowl- 
edgeable experts. Nevertheless, they have been remarkably useful and often among the first indications of an outbreak. During the Kikwit Ebola outbreak in 1995, it was rumored that a local Reuters dispatch from January had described an outbreak but was not widely noticed (or available).

- Verification methods. Several years ago, the WHO (under the able leadership of David Heymann, then executive director for communicable disease surveillance and response) launched an Outbreak Verification List for follow-up of key outbreak reports from these and other unofficial sources. These sources can provide agencies such as the WHO or the CDC with very useful information and can be used to help compel governments to report outbreaks sooner than they might otherwise. At the same time, just as with media reports, the effects are not always controllable.

- Internet and cell phones. The Internet has now expanded into many parts of the world, even in low-income countries. One promising idea for developing countries is connecting remote clinics or health centers to the Internet, using satellite connections when necessary. This was done in the past by SatelLife, partnering with ProMED, and more recently in Haiti by Partners in Health. ${ }^{30}$ However, resource limitations leave critical needs for additional solutions appropriate to these areas. Voxiva uses short messaging system (SMS) or Web-based forms to report various disease emergencies via cell phone. Numeric codes can be used to represent various types of symptoms or disease emergencies, which are transmitted to a central office. ${ }^{31}$ With the wide availability of cell phones now, even in many low-income villages, this ingenious approach could alert authorities rapidly to a problem. Following on outbreak-reporting projects in Peru and Rwanda, Voxiva is now working in Indonesia to report cases of suspected avian flu. ${ }^{32}$

\section{Progress Over The Past Ten Years}

How do early warning capabilities of today compare with the situation of ten years ago? ${ }^{33}$ To be sure, much progress has been made. ${ }^{34}$
National systems in many countries, including the United States, Canada, Thailand, China, and Vietnam (as just a few examples), have expanded. As already discussed, electronic networks have been developed, and in recent years, the WHO has begun both collecting and providing information in near real timefor example, on its Web site. In recent years, the WHO has developed a "network of networks," the Global Outbreak and Response Network (GOARN), with information from a wide variety of sources; expanded its influenza surveillance; and revised the International Health Regulations to report a broader scope of infectious diseases, including the possibility of emerging infections. ${ }^{35}$

There has also been recent progress in attempts at more-effective data aggregation and sharing at the national and international regional levels. In the United States, the CDC's BioSense is designed to collect clinical data from hospitals, laboratories, and other providers for early event detection and eventually to feed into the DHS National Biosurveillance Integration System (NBIS), the national "umbrella" for bringing together relevant data. ${ }^{36}$ There have also been some similar efforts in other areas of the world, such as MedISys, from the U.K. government and including several other counties. The WHO's GOARN network of networks has been mentioned, and there are current efforts to link the WHO and international animal disease databases.

\section{Recommendations For Further Progress}

These are indications of real progress. Nevertheless, despite these improvements, it is equally obvious that more is needed. Here are a few suggestions.

(1) Coordinate reporting systems worldwide, and ensure compatible standards for aggregating and sharing data. This must begin, of course, with coordinating human disease reporting. Consider strategies for also identifying emerging infections, as in the 1996 ProMED proposal or IHR (2005). As soon as feasible, improve data sharing and coordination between human and animal health re- 
sources. A possible prototype for the latter might be the European MedVetNet (http:// www.medvetnet.org/cms). The WHO would seem a likely venue for bringing these elements together globally.

(2) Encourage improvements by providing additional resources. The highest-yield investments include coordinating information systems and implementing exchangeable electronic medical records; personnel training; improving epidemiologic capacity at the regional or national levels; and providing communications infrastructure. Increasing diagnostic laboratory capacity also remains an issue. To encourage international cooperation, the established capabilities of the CDC and other agencies (for example, the Institut Pasteur network) for providing international assistance and training should be augmented.

(3) Further encourage clinicians and health officials to report by providing useful feedback, to provide rapid communications and, when needed, timely assistance in response. This can enable every clinician to be the "proverbial astute clinician." (4) Provide funding and incentives for full implementation of the new International Health Regulations. (5) For developing countries where clinicians are in short supply, train local people to recognize and report (or even respond to) some types of local outbreaks (as in the Voxiva example).

(6) Educate policymakers to consider disease surveillance a priority. These are global problems, and it is in everyone's interest to ensure that the necessary resources are available to all. Prompt reporting and providing accurate and timely public information can save many lives, increase trust in government, and avert more-serious consequences.

It should be noted, using the health intelligence analogy, that most of our efforts to date have focused on collection (that is, reporting), with some focus on action and relatively little focus on analysis. Although this might be largely a result of the rate-limiting nature of the reporting or data collection step, ways to improve analysis and disease response must also be developed.

\section{When To Respond?}

A survey of global surveillance returns us to the earlier example of an influenza pandemic. Influenza surveillance is one of the best existing systems worldwide. ${ }^{37}$ But to prevent a pandemic, early warning when the virus reaches the United States or western Europe is not sufficient. Given the speed with which such an infection (even SARS, for that matter) could travel, it would be far more desirable to have early warning at the source. But it is also essential to have appropriate response, including both good response plans and effective response capabilities.

All of this information has to be translated into information that policymakers can understand and use. For action, this leads to the inevitable dilemma: When to respond (and, for that matter, when to stop)? There is as yet no definite answer. Some preliminary suggestions can be sketched briefly, to encourage further thought on this critical issue. Overreacting too often causes political difficulties and can lead to responder fatigue, in which many warnings of events that do not materialize make it difficult or impossible to mobilize an effective response when needed. Some professionals, especially in Canada, felt that the WHO overreacted in issuing travel advisories during the SARS outbreak in 2003. On the other hand, past responses have often been too little and too late. The question of triggers for response therefore remains crucial, with both scientific and political dimensions. The WHO has recently revised its global pandemic influenza preparedness plan to begin incorporating some risk-based triggers, the last two phases being when fewer than twenty-five people are infected in cases lasting less than two weeks and when there is "a cluster of 25-50 cases...lasting from 2 to 4 weeks." ${ }^{38}$ While quantitatively a great improvement, 
these criteria are still essentially arbitrary. For influenza, even two weeks may be too late. Recent papers modeling a hypothetical $\mathrm{H} 5 \mathrm{Nl}$ influenza pandemic suggest that the pandemic could be prevented if (and perhaps only if) targeted disease-control measures began before more than forty people were infected. ${ }^{39}$ This figure suggests urgency. It is borne out by experience with the global spread of SARS, which is much less transmissible than most human flu viruses but which started its worldwide spread with the infection of only a few people in Hong Kong.

We should further develop more-rigorous criteria for triggers, based on epidemiologic criteria such as transmissibility. There is also some evidence that at least some pandemics have been preceded by a "herald wave" or other foreshadowings, for reasons that are still unclear. ${ }^{40}$

$\mathrm{T}$ O MANY, THE DEVELOPMENT of truly effective global systems of infectious disease surveillance (and, ultimately, health intelligence) is often relegated to the "too hard" category. In reality, the problems are challenging, but not insoluble. Although the goal is ambitious, we are fortunate to have better tools (such as rapid global communications, electronic monitoring of health data, and rapid molecular diagnostics) and more potential resources than ever before. The increasing number of infections that are continuing to appear, and their greatly increased opportunities for rapid global spread, make the goal both rewarding and essential to our own survival.
This research was funded by Cooperative Agreement no. U90/CCU224241 from the Centers for Disease Control and Prevention (CDC) and no. 5U54AI057158-02 from the National Institute of Allergy and Infectious Diseases (NIAID), the U.S. Government Strategic Assessments Group, and the Arts and Letters Foundation. The author is grateful to Christopher Decker; to Pamela Noe for the term "health intelligence"; to Ruth Berkelman, Joy Miller, and Tara O'Toole for invaluable discussions; and to the editors and two anonymous reviewers for their helpful comments.

\section{NOTES}

1. J. Lederberg, R.E. Shope, and S.C. Oaks Jr., eds., Emerging Infections: Microbial Threats to Health in the United States (Washington: National Academies Press, 1992).

2. N.M. Ferguson et al., "Strategies for Containing an Emerging Influenza Pandemic in Southeast Asia," Nature 437, no. 7056 (2005): 209-214; and I.M. Longini Jr. et al., "Containing Pandemic Influenza at the Source," Science 309, no. 5737 (2005): 1083-1087.

3. J.M. Barry, The Great Influenza (New York: Viking Penguin, 2004); and A.W. Crosby, America's Forgotten Pandemic: The Influenza of 1918 (rev. ed.) (New York: Cambridge University Press, 2003).

4. M.S. Smolinski, M.A. Hamburg, and J. Lederberg, eds., Microbial Threats to Health: Emergence, Detection, and Response (Washington: National Academies Press, 2003).

5. Ferguson et al., "Strategies for Containing an Emerging Influenza Pandemic"; and Longini et al., "Containing Pandemic Influenza."

6. World Health Organization, "Summary of Probable SARS Cases with Onset of Illness from 1 November 2002 to 31 July 2003 (revised 26 September 2003)," http://www.who.int/csr/sars/country/ table2003_09_23/en/index.html (accessed 6 October 2006).

7. S.S. Morse and A. Schluederberg, "Emerging Viruses: The Evolution of Viruses and Viral Diseases," Journal of Infectious Diseases 162, no. 1 (1990): $1-7$.

8. S.S. Morse, "Factors in the Emergence of Infectious Diseases," Emerging Infectious Diseases 1, no. 1 (1995): 7-15.

9. A.D. Langmuir, "The Surveillance of Communicable Diseases of National Importance," New England Journal of Medicine 268 (1963): 182-192.

10. S.S. Morse et al., "ProMED Global Monitoring of Emerging Diseases: Design for a Demonstration Program," Health Policy 38, no. 3 (1996): 135-153; 
and S.S. Morse and J.M. Hughes, "Developing an Integrated Epidemiologic Approach to Emerging Infectious Diseases," Epidemiologic Reviews 18, no. 1 (1996): 1-3.

11. M.M. Wagner, A.W. Moore, and R.M. Aryel, Handbook of Biosurveillance (Burlington, Mass.: Elsevier Academic Press, 2006).

12. Morse et al., "Global Monitoring of Emerging Diseases."

13. R. Heffernan et al., "System Descriptions: New York City Syndromic Surveillance Systems," Morbidity and Mortality Weekly Report 53 Supp. (2004): 23-27.

14. D.M. Bravata et al., "Systematic Review: Surveillance Systems for Early Detection of Bioterrorism-Related Diseases," Annals of Internal Medicine 140, no. 11 (2004): 910-922; and A. Reingold, "If Syndromic Surveillance Is the Answer, What Is the Question?" Biosecururity and Bioterrorism 1, no. 2 (2003): 77-81.

15. W.G. Downs, "Malaria: The Great Umbrella," Bulletin of the New York Academy of Medicine 51, no. 8 (1975): 984-990.

16. James M. Hughes, CDC, personal communication, November 1998.

17. D. Normile, "Avian Influenza: WHO Faults China for Lax Outbreak Response," Science 309, no. 5735 (2005): 684; and K.T. Greenfeld, China Syndrome: The True Story of the Twenty-first Century's First Great Epidemic (New York: HarperCollins, 2006).

18. WHO, "International Health Regulations (IHR)," http://www.who.int/csr/ihr/en (accessed 6 October 2006).

19. International Society for Infectious Diseases, ProMED-mail, Archive 20030211.0369, http:/ www.promedmail.org (accessed 22 March 2007).

20. J.-W. Lee and W.J. McKibbin, "Estimating the Global Economic Costs of SARS," in Learning from SARS: Preparing for the Next Disease Outbreak-Workshop Summary (Washington: National Academies Press, 2004), 92-109.

21. National Advisory Committee on SARS and Public Health, Learning from SARS-Renewal of Public Health in Canada (Ottawa: Health Canada/ Public Health Agency of Canada, 2003).

22. Q.Y. Zhu et al., "Fatal Infection with Influenza A (H5Nl) Virus in China," New England Journal of Medicine 354, no. 25 (2006): 2731-2732.

23. Ruth Berkelman, professor, Rollins School of Public Health, Emory University, personal communication, December 2005.

24. The information is based on the author's discussions with several participants.
25. Morse et al., "Global Monitoring of Emerging Diseases."

26. D.A. Henderson, "Surveillance Systems and Intergovernmental Cooperation," in Emerging Viruses, ed. S.S. Morse (New York and Oxford: Oxford University Press, 1993), 283-289.

27. Morse et al., "Global Monitoring of Emerging Diseases."

28. ISID, ProMED-mail, Archives.

29. Morse et al., "Global Monitoring of Emerging Diseases."

30. H.S. Fraser et al., "An Information System and Medical Record to Support HIV Treatment in Rural Haiti," British Medical Journal 329, no. 7475 (2004): 1142-1146.

31. C.K. Prahalad, "The Voxiva Story," in The Fortune at the Bottom of the Pyramid (Upper Saddle River, N.J.: Wharton School Publishing/Pearson, 2005), 361-379.

32. N. Zamiska, "Fighting Bird Flu with Cellphones; Indonesia Goes Wireless to Overcome Reporting Delays on Cases of Deadly Disease," Wall Street Journal, 17 August 2006.

33. R.L. Berkelman et al., "Infectious Disease Surveillance: A Crumbling Foundation,” Science 264, no. 5157 (1994): 368-370.

34. S.S. Morse, "Viral Traffic on the Move," Issues in Science and Technology 19, no. 4 (2003): 43-44.

35. WHO, "International Health Regulations (IHR)."

36. For more information on the CDC's BioSense, go to http://www.cdc.gov/biosense (accessed 22 March 2007).

37. For a description of the U.S. system, see CDC, "Flu Activity: Reports and Surveillance in the United States," http://www.cdc.gov/flu/weekly/ fluactivity.htm. The global components are described at WHO, "Global Influenza Surveillance," http://www.who.int/csr/disease/ influenza/influenzanetwork/en/index.html (both accessed 22 March 2007).

38. WHO, Global Pandemic Influenza Preparedness Plan (Geneva: WHO, 2005). The WHO may be in the process of revising the criteria.

39. Longini et al., "Containing Pandemic Influenza."

40. D.R. Olson et al., "Epidemiological Evidence of an Early Wave of the 1918 Influenza Pandemic in New York City," Proceedings of the National Academy of Sciences (U.S.) 102, no. 31 (2005): 11059-11063. 